\title{
Femtosecond Laser in Polymeric Materials: Microfabrication of Doped Structures and Micromachining
}

\author{
Daniel S. Correa, Marcos R. Cardoso, Vinicius Tribuzi, Lino Misoguti, and Cleber R. Mendonca
}

(Invited Paper)

\begin{abstract}
The use of laser light to modify the material's surface or bulk as well as to induce changes in the volume through a chemical reaction has received great attention in the last few years, due to the possibility of tailoring the material's properties aiming at technological applications. Here, we report on recent progress of microstructuring and microfabrication in polymeric materials by using femtosecond lasers. In the first part, we describe how polymeric materials' micromachining, either on the surface or bulk, can be employed to change their optical and chemical properties promising for fabricating waveguides, resonators, and selfcleaning surfaces. In the second part, we discuss how two-photon absorption polymerization can be used to fabricate active microstructures by doping the basic resin with molecules presenting biological and optical properties of interest. Such microstructures can be used to fabricate devices with applications in optics, such as microLED, waveguides, and also in medicine, such as scaffolds for tissue growth.
\end{abstract}

Index Terms-Laser ablation, laser excitation, laser material processing applications, optical polymers, two-photon absorption (TPA).

\section{INTRODUCTION}

$\mathbf{T}$ HE miniaturization of devices has been pursued by scientists in the last decades, due to the need for producing more compact and efficient equipment, for applications in microfluidics, micromechanics and microelectromechanical systems (MEMS), biochips, photonics, etc. Among the techniques employed in the miniaturization of devices and fabrication of micro/nanostructures are the layer-by-layer (LBL) technique [1], [2], electrochemical deposition [3], lithography, soft lithography [4], laser-induced chemical vapor deposition [5], and others. Most of these methods, however, are limited to microfabricating surfaces, being, therefore, not capable of producing 3-D structures. In the last few years, ultrashort laser microstructur-

Manuscript received October 18, 2010; revised December 30, 2010; accepted January 4, 2011. Date of publication March 21, 2011; date of current version January 31,2012 . This work was supported in part by the Brazilian agencies Fundação à Pesquisa do Estado de São Paulo, Conselho Nacional de Desenvolvimento Científico e Tecnológico, Coordenação de Aperfeiçoamento de Pessoal de Nivel Superior.

D. S. Correa is with Embrapa Instrumentação, 13560-970, São Carlos, Brazil (e-mail: daniel@cnpdia.embrapa.br).

M. R. Cardoso, V. Tribuzi, L. Misoguti, and C. R. Mendonca are with the Instituto de Física de São Carlos, Universidade de São Paulo, Caixa, São Carlos 13560-970, SP, Brazil (e-mail: cardosomr@ifsc.usp.br; tribuzi@ ursa.ifsc.usp.br; misoguti@ifsc.usp.br; crmendon@if.sc.usp.br).

Color versions of one or more of the figures in this paper are available online at http://ieeexplore.ieee.org.

Digital Object Identifier 10.1109/JSTQE.2011.2106764 ing has received considerable attention because of its precision and ability to structure materials in 3-D. Furthermore, the use of such methods has become widespread thanks to the range of laser sources available and the flexibility they provide. In laser microstructuring, a focused laser beam is used to microstructure materials, taking advantage of nonlinear optical interactions. In addition to the use of ultrashort laser pulses to ablate or modify structural properties of materials, a new technology has appeared recently to allow building 3-D structures. This approach, called two-photon absorption (TPA) polymerization [6], provides resolution in the nanometer scale, relatively high production speed, and ability to create complex 3-D structures. The key advantage of using TPA polymerization to fabricate microstructures is related to the ability of hardening the polymeric resin in a tiny spatial region. In addition, by selecting distinct photopolymers and photoinitiators, one can incorporate doping materials into the resin formulation, including dyes, metals and ceramics, enhancing the properties of the final structure. In this paper, we present some results our group has obtained on the femtosecond (fs)-laser micromachining of polymers and on the two-photon polymerization microfabrication of doped microstructures, with potential implication on photonic devices and biology.

\section{Modification of a Polymeric MATERIAL BY AN FS LASER}

\section{A. FS-Laser Micromachining in Polymers}

The use of ultrashort laser pulses for micromachining transparent materials has been applied in the fabrication of several optical devices, such as, for instance, amplifiers, resonators, waveguides, and switches, most of them in glass [7]-[9]. In the last few years, however, this technique has started being explored to fabricate photonic devices in polymers [10]-[13]. Polymeric materials are promising candidates for photonic devices mainly because their optical properties can be modified by chemical synthesis or doping, which allows tailoring for specific applications. Although there are several methods capable of structuring polymers in a low-cost and reproducible way, most of them-standard photolithography, electron beam writing, or photopatterning in photosensitive polymers [4], [14]-[17]—are limited to structuring only the sample's surface. FS-laser micromachining, on the other hand, allows a precise manner to structure also in 3-D. 
When fs pulses are focused into a material, the light intensity at the focal volume can be enough to induce nonlinear optical effects. The light absorption in a transparent material is nonlinear because the incident photons do not have enough energy to promote electronic transition in the material by single-photon absorption. However, highly intense and tightly focused laser pulses can achieve an electric field with magnitude comparable to the ones that binds the electrons in atoms or molecules (as high as $10^{8} \mathrm{~V} / \mathrm{m}$ ) [18], [19] thus, inducing the nonlinear optical phenomena of multiphoton absorption. Such a localized multiphoton absorption process leads to structural changes in the material [20], [21], which can be used to produce distinct types of devices. For example, when the index of refraction is modified, waveguides can be written enabling the 3-D integration of photonics devices [22], [23].

The intensity needed to produce changes or damage in materials is determined by the pulse energy $E$, the pulse duration $\tau$, and the beam focusing numerical aperture NA. In general, the maximum $E$ and the minimum $\tau$ are given by the specific laser system being used. For fixed values of $\tau$ and NA, the absorption depends basically on $E$; the smallest value of $E$ that produces multiphoton absorption and, consequently, changes in the material is the threshold energy. If $E$ is kept close to the threshold, the changes will be localized only to the vicinity of the focus. On the other hand, if $E$ is increased above the threshold, the region affected by the laser is also increased. The NA basically determines the width of the focal volume and, consequently, the feature size of the micromachining. The NA also impacts on the geometry of the structure. When NAs higher than 0.6 are used, spherically symmetric features are produced. Conversely, for NAs smaller than 0.6 asymmetric structures are created. Overall, ultrashort laser micromachining in polymers can be achieved only with energies per pulse of nanojoules, which can be obtained through laser oscillators (not amplified systems). Ti:sapphire laser oscillators typically have megahertz repetition rates and pulses on the order of 50-100 fs [7], [20], [21], [24]. For the so-called oscillator-only-micromachining, the time between pulses (tens of nanoseconds) is smaller than the heat diffusion characteristic time (on the order of microseconds for micrometric focal volumes) [7], [20], [21], [24], 25], conferring an accumulative nature to the micromachining. Some papers studying fundamental aspects of the micromachining process as well as the fabrication of devices, mostly in transparent materials, can be found in the literature [11], [12], [26]-[31]. In our group, we have focused on the investigation of fs-laser micromachining either in polymers doped with organic compounds with interesting optical properties, or in polymeric materials presenting special properties (optical, electrical, or biological).

\section{B. Two-Photon Absorption Polymerization Microfabrication}

The two-photon absorption (TPA), which was theoretically predicted by Maria Goeppert Mayer in 1931, states that an atom or a molecule can undergo an electronic transition by simultaneously absorbing two photons in a single quantum event. Although the TPA probability is too low to be measured by conventional light excitation [32], it can be observed when in- tense laser light is used. By using fs-laser pulses in a nonlinear material, the TPA rate can reach values of few events per second, which is possible to be measured. As a consequence of the high light intensity required for the experimental observation of TPA, it became more popular after the invention of the laser in the 1960s. The first experimental observation of fluorescence induced via TPA was carried out in 1961 in a $\mathrm{CaF}_{2}: \mathrm{Eu}^{+2}$ crystal using a Ruby laser [33].

The TPA rate displays a quadratic dependence on light intensity, which provides high spatial resolution and low light scattering, because of the nonlinear nature of the process and use of longer wavelengths. These features have impelled TPA to be used in several technological applications, such as optical limiting, TPA fluorescence microscopy, optical data storage, photodynamic therapy, and TPA polymerization [34]-[36].

In polymerization, molecules of low molecular weight, called monomers, are chemically reacted to form a macromolecule or a polymer chain. The starting point for the chemical reaction is to form radical species, which, in the case of conventional (one-photon) photopolymerization, are obtained by exposing the initiating molecule to standard light. However, in TPA polymerization, electronic transition of the initiating molecule occurs by simultaneous absorption of two photons. In such a case, absorption takes place only in a confined spatial region (focal volume), and as a consequence, radical formation (in the case of radicalar polymerization) and polymerization occur on the vicinity of the focused laser beam. Due to this feature, twophoton absorption polymerization has been proposed as a tool for fabricating micro- and nanodevices [19], [37]-[40].

As TPA polymerization requires a high-intensity light source, objective lenses are employed to focus the laser beam into the sample. As an outcome, there is a physical limit imposed to the laser beam waist, given by the diffraction limit. In the case of a light source with uniform intensity profile, the focused beam presents an intensity profile given by the Airy disc [41], yielding a minimum beam waist $D=1.22 \lambda / \mathrm{NA}$, where $\lambda$ is the excitation wavelength and NA is the objective numerical aperture. For instance, if we employ an excitation wavelength of $780 \mathrm{~nm}$ and an objective with NA $=0.5$, the diffractionlimited spot size would be nearly $1900 \mathrm{~nm}$. In practice, however, due to its nonlinear nature, which depends on the square of the intensity, TPA polymerization overcomes the diffraction-limited spot size, enabling polymerization of much smaller voxels.

Polymerization threshold is another key feature in TPA polymerization, and it is related to the production of initiating species from the photoinitiator triplet state, which is given by the quantum efficiency of initiation. The performance of the polymerization threshold depends on the individual mechanisms of the photochemical reactions. In the radical polymerization, molecular oxygen plays an important role [19], because it may suppress the polymerization through two specific routes: 1) suppression of the triplet state of the photoinitiator by energy transfer to oxygen and 2) suppression of the triplet state of the photoinitiator through a direct reaction with oxygen, leading to the formation of peroxide radical, which is less reactive than the radical itself. Both routes can be used to limit the voxel size, once they compete with the polymerized voxel formation [19]. By 


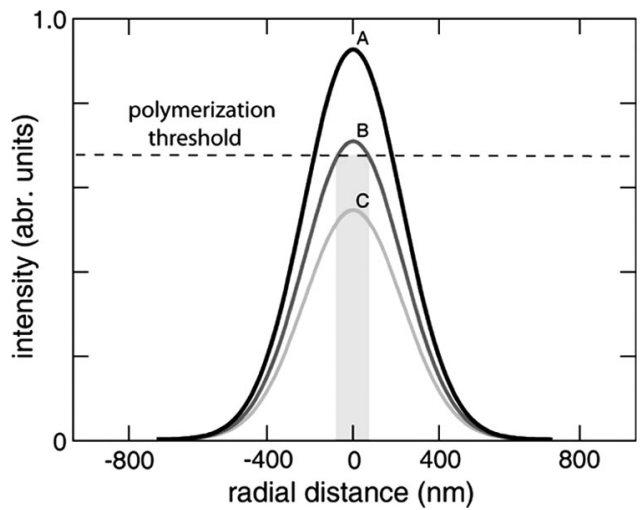

Fig. 1. Distribution of light intensity for a Gaussian laser beam. A, B, and $\mathrm{C}$ denote intensity levels above, slightly above, and below the polymerization threshold (dashed line), respectively.

controlling the intensity of light in the focal volume, it becomes possible to reach a situation where the radicals formed by TPA survive, initializing the polymerization only in the region where the laser energy is higher than the polymerization threshold, enabling the confection of structures with feature size below the diffraction limit. Such a situation is illustrated in Fig. 1, which shows a radial distribution of the light intensity for a Gaussian laser beam. In this figure, A, B, and C denote intensity levels above, slightly above, and below the polymerization threshold (dashed line), for a hypothetical TPA polymerization. For both $\mathrm{A}$ and $\mathrm{B}$ intensity levels, TPA polymerization takes place, although B allows polymerizing voxels with size features below the diffraction limit.

\section{EXPERIMENTAL SETUP}

\section{A. FS-Laser Micromachining in a Polymer}

In general, laser micromachining is carried out by focusing the laser light into the sample volume or surface, while the beam is scanned or the sample translated. As mentioned earlier, the light intensity achieved at the focus can be sufficient to cause multiphoton absorption, leading to optical breakdown in the material. The nonlinear nature of the absorption localizes the process to the vicinity of the focal volume. The amount of energy deposited in the material may produce permanent structural changes, degradation or ablation of the material.

The samples were micromachined using laser pulses centered at $800 \mathrm{~nm}$, with temporal duration of approximately 100 fs, delivered from a Kerr-lens mode-locked Ti:sapphire oscillator ( $\sim 80 \mathrm{MHz}$ repetition rate). Pulses with energies of only a few nanojoules are enough to micromachining polymers. Besides, the temporal interval between pulses for oscillatoronly-micromachining, as the one described here, is smaller than the heat diffusion time. Therefore, the micromachining process presents an accumulative nature. The laser beam is focused into the sample by microscope objectives with distinct numerical apertures (NAs). This parameter determines the width of the focal volume and, consequently, the feature size of the micromachined area. The range of NA employed spans from 0.25 to 0.6. The sample is placed on a computer-controlled $x-y-z$ stage,

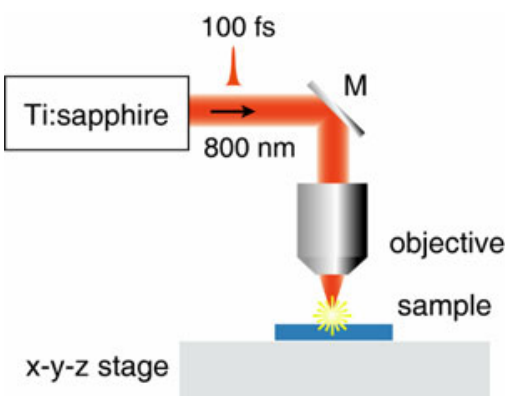

Fig. 2. Scheme of the experimental setup used for fs-laser micromachining.

which moves the sample with a constant speed, while the objective lens remains fixed. The basic experimental setup used for the micromachining is illustrated in Fig. 2.

The micromachined samples were analyzed by optical microscopy, atomic force microscopy, and fluorescence microscopy. The optical properties of the samples were evaluated by measuring their UV-vis absorption spectrum.

\section{B. TPA Polymerization Microfabrication}

The resin we employed in the TPA polymerization fabrication consists of a mixture of two tri-acrylate monomers: tris(2hydroxyethyl)isocyanurate triacrylate (SR368) and ethoxylated(6) trimethylolpropane triacrylate (SR499). The first one increases the microstructure hardness, while the second one reduces shrinkage upon polymerization. As TPA photoinitiator, we use ethyl-2,4,6-trimethylbenzoylphenylphosphinate, commercially known as Lucirin TPO-L, which has been proven to be a suitable photoinitiator for TPA polymerization [42], [43].

The experimental setup used to fabricate the structures consists of a Ti:sapphire laser oscillator system (100 fs and $800 \mathrm{~nm}$ ). The laser beam is focused onto the sample with a $0.65-\mathrm{NA} \mathrm{mi-}$ croscope objective. The average power, depending on the dopant employed in the resin formulation, ranges from $10 \mathrm{~mW}$ up to $40 \mathrm{~mW}$, measured before the objective. The sample is prepared by placing a drop of resin on a glass substrate, which lies on a glass slide. The resin is retained inside a spacer and enclosed by a cover slip. The sample is positioned in the axial $z$ direction using a motorized stage, while the laser is scanned across the sample in the $x y$ plane using a pair of galvano mirrors. After the desired microstructure is fabricated, the sample is immersed in ethanol to wash away the unsolidified resin, leaving behind the desired structure on the glass substrate. A charge-coupled device (CCD) camera is coupled to the experimental setup to monitor TPA polymerization in real time. An illustration of the experimental setup (inverted microscope scheme) is displayed in Fig. 3.

\section{RESULTS AND DISCUSSION}

\section{A. FS-Laser Micromachining in Polymers}

1) Micromachining a Conjugated Polymer: Poly[2-methoxy-5-(2'-ethylhexy-loxy)-p-phenylene vinylene] (MEH-PPV) is a conjugated polymer that presents interesting optical and electrical properties, being therefore a potential candidate 


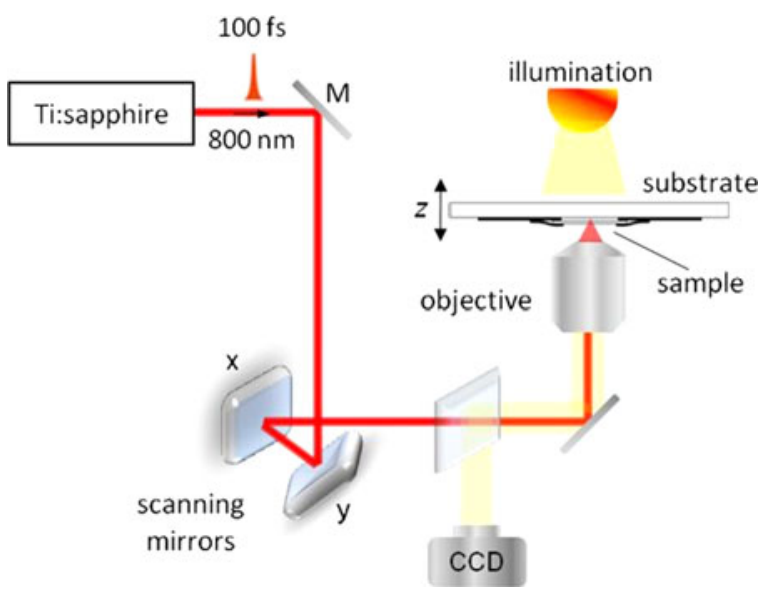

Fig. 3. Scheme of the experimental setup employed for the TPA polymerization.

for fabricating optoelectronic devices such as organic lightemitting diodes, chemical sensors, semiconductors, and flexible displays [44], [45]. 350-nm thick films of MEH-PPV were produced by spin-coating a chloroform solution of the polymer ( 5 $\mathrm{mg} / \mathrm{ml}$ ) in a glass substrate.

In [46], MEH-PPV samples were micromachined at a translation speed of $20 \mu \mathrm{m} / \mathrm{s}$ and pulse energies from 0.07 up to $2.4 \mathrm{~nJ}$. The threshold energy for inducing visible modification in the MEH-PPV sample was determined to be $0.05 \mathrm{~nJ}$. We observed that the $\pi \rightarrow \pi^{*}$ absorption band of MEH-PPV, located around $500 \mathrm{~nm}$, decreases its magnitude as the pulse energy used for micromachining is increased, indicating sample photobleaching upon micromachining due to photooxidation of the polymer [47], [48]. However, a decrease in the absorption peak of about $62 \%$ was obtained for the sample micromachined at an energy of $0.89 \mathrm{~nJ}$, revealing that unbleached MEH-PPV remains in the sample, provided that the right range of pulse energy is respected [46]. These results suggest that the polymer's conductive properties may also be preserved after the fs-laser micromachining if the correct energy regime is used. We also observed that the micromachined areas of MEH-PPV preserve its characteristic fluorescent emission (around $600 \mathrm{~nm}$ ), although with smaller intensity if compared with the nonirradiated areas [46]. Such result corroborates that MEH-PPV electrical properties may be preserved after the micromachining, depending on the energy employed.

Our results revealed two distinct micromachining regimes as a function of pulse energy [46], as shown by the two representative atomic force micrographs of grooves fabricated at pulse energies of 0.3 and $2.0 \mathrm{~nJ}$, displayed in Fig. 4.

The atomic force micrographs also show an increase in the average surface roughness of the micromachined region, being about $10 \mathrm{~nm}$ below the ablation threshold and $50 \mathrm{~nm}$ above it [46]. Similar results have also been observed for poly(methylmethacrylate), although the surface roughness can be decreased by thermal annealing if smoother surfaces are required [29], [31].

The depths of grooves, determined by atomic force microscopy, are plotted as a function of pulse energy in Fig. 5.

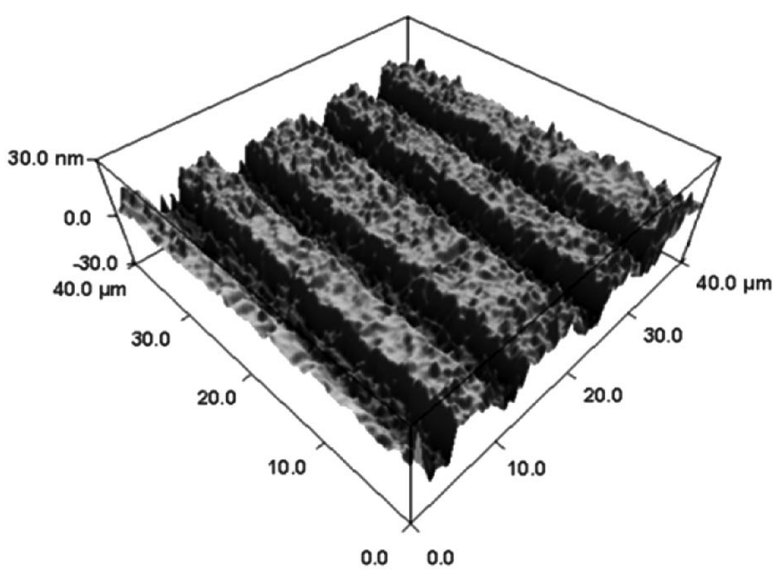

(a)

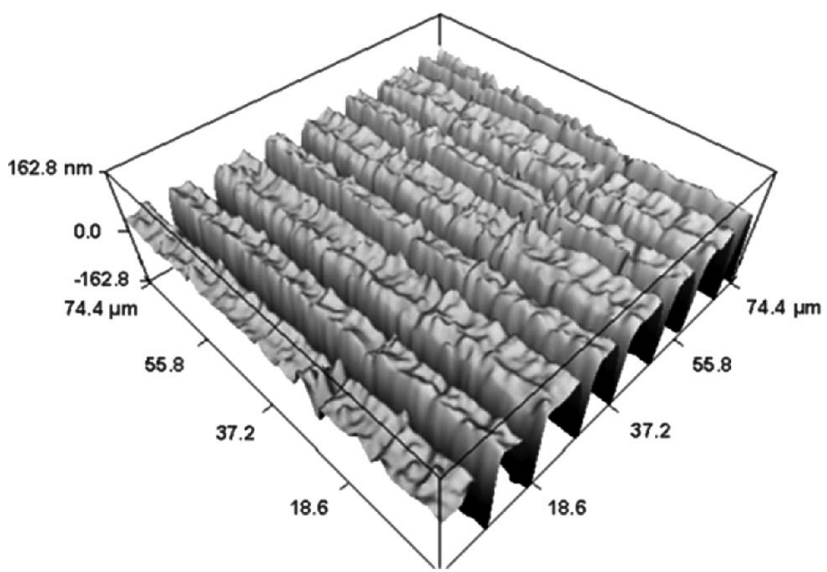

(b)

Fig. 4 Atomic force micrograph of grooves micromachined in MEH-PPV films with pulse energies of (a) $0.3 \mathrm{~nJ}$ and (b) $2.0 \mathrm{~nJ}$. Reprinted from [46]. Copyright [2007], with permission from Elsevier.

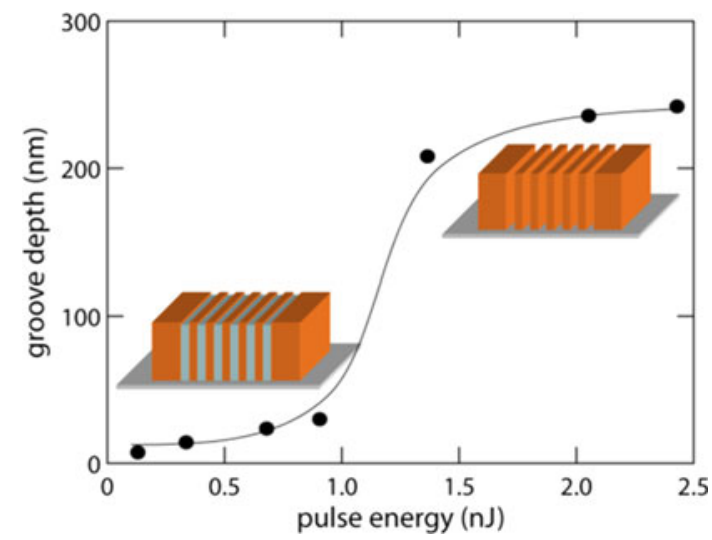

Fig. 5. Depth of the grooves as a function of the pulse energy for a translation speed of $20 \mu \mathrm{m} / \mathrm{s}$. The inset illustrates the two distinct micromachining regimes achieved. Reprinted from [46]. Copyright [2007], with permission from Elsevier.

As seen in Fig. 5, material is only slightly removed from the sample surface for pulse energies up to $1 \mathrm{~nJ}$. The maximum groove depth in this case is approximately $30 \mathrm{~nm}$, which represents less than $10 \%$ of the sample thickness. Conversely, for energies higher than $1.4 \mathrm{~nJ}$ the depths of the fabricated grooves are of the order of the film thickness $(250 \mathrm{~nm})$. As illustrates in 
the inset of Fig. 5, depending on the pulse energy employed for the micromachining, polymer removal, surface modification or photobleaching can be achieved [46]. Therefore, fs-laser micromachining seems to be an interesting option for the development of applications in conjugated polymers based devices.

2) Micromachining a Polymer Containing Azoaromatic Chromophores: Poly (methyl methacrylate) (PMMA) is one of the polymers mostly used for the development of optical components due to its high transmission in the visible and nearinfrared [49]. This has motivated in recent years the fabrication of waveguides by fs-laser micromachining in pure PMMA, as well as in other nondoped polymers [11]. However, this technique has not been much exploited for polymeric matrixes doped with optically active organic molecules. Hence, our research in this field has been focused toward this direction. Here, we summarize some results we obtained on the use of fs-laser micromachining in PMMA doped with azoaromatic chromophores, specifically Disperse Red 1 (DR1), Disperse Red 13 (DR13), and Disperse Orange 3 (DO3) [25]. Azoaromatic chromophores present attractive linear and nonlinear optical properties, which have motivated their study for the development of devices, such as, for example, second-harmonic generators [50] and birefringence-based optical storage [51], [52].

The samples were micromachined using 130-fs, 800-nm laser pulses from a laser oscillator operating at $76 \mathrm{MHz}$. The threshold energy at which change occurs in the samples decreases with the azochromophore concentration, and scales with the TPA of the dyes at $800 \mathrm{~nm}$ [53], [54]. Such a result indicates that the micromachining, in this case, is driven by the TPA of the azochromophores [25]. For pure PMMA, the surface damage was determined to be $0.54 \mathrm{~nJ}$, and is related to a multiphoton absorption. On the other hand, for the doped samples the threshold is much smaller. For example, the threshold energy for a PMMA sample containing 1\% (by weight) of DR1 was measured to be $0.11 \mathrm{~nJ}$. Thus, doping substantially decreases the threshold energy. It is important to mention that when an energy of $0.54 \mathrm{~nJ}$ is employed to micromachine the doped polymers, sample carbonization is obtained.

A decrease in the $\pi \rightarrow \pi *$ absorption band of the azochromophores occurs after fs-laser micromachining for the doped PMMA samples, which was attributed to photodegradation. It has been shown that photodegradation of azochromophores is mainly due to photooxidation, being also dependent on the polymeric matrix, temperature, and environment and [55], [56]. Therefore, molecules presenting large oxidation potentials are the most stable ones. Such behavior can be observed in the micromachined samples, since the decrease in absorbance is smaller for DR13 that presents higher oxidation potential than DO3 and DR1 [55], [56]. In fact, the observed photobleaching for DR13 is negligible for the energy range used (energies ranging from $0.01 \mathrm{~nJ}$ to $0.2 \mathrm{~nJ}$ ).

In Fig. 6(a), we present an optical microscopy image of two waveguides, separated by about $200 \mu \mathrm{m}$, fabricated by fs-laser micromachining in the bulk of a thick DR1-doped PMMA sample [25].

The waveguides were written along the $5 \mathrm{~mm}$ length of the sample. The cross-sectional view exhibited in Fig. 6(b) reveals

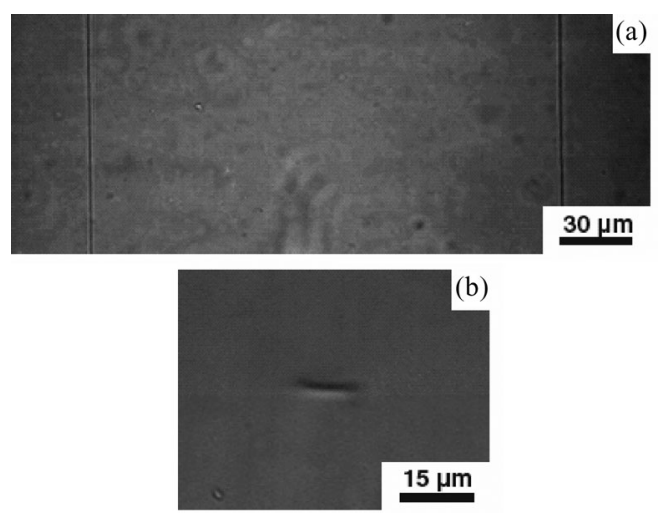

Fig. 6. (a) Optical microscope image of waveguides micromachined in PMMA doped with DR1 written at a speed of $20 \mu \mathrm{m} / \mathrm{s}$. (b) Cross section of the waveguides fabricated. Reprinted from [25]. Copyright [2008], with permission from Optical Society of America.
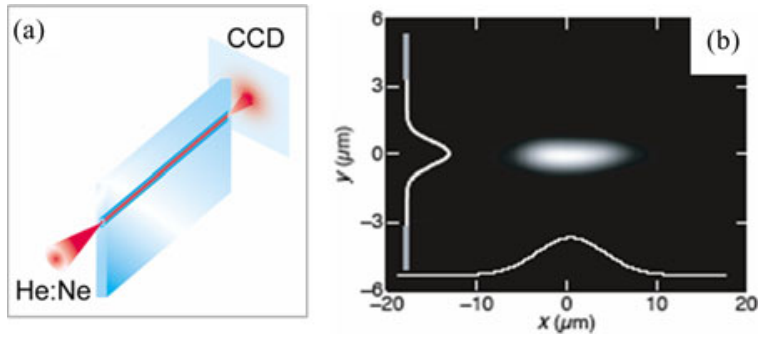

Fig. 7. (a) Basic concept of the experimental setup used to check the waveguiding in the fabricated sample. (b) Output image of the single-mode profile of 632.8-nm light coupled through the waveguide, along with the spatial intensity distribution of the profile. Reprinted from [25]. Copyright [2008], with permission from Optical Society of America.

an elongated profile, probably related to the Rayleigh range of the objective used to fabricate the waveguide [7]. Since the waveguide was fabricated using a high-repetition laser, accumulative effects take place because the interval between consecutive pulses is shorter than the thermal diffusion. In this way, the region around the focus is heated up and, subsequently, cooled down when the area is translated away of focus. Hence, the polymer resolidifies leading to a change in the index of refraction, yielding waveguiding.

The waveguiding of the fabricated structures was verified by coupling light, from a HeNe laser operating at $632.8 \mathrm{~nm}$, in and out the waveguide, which was carried out with the aid of two $10 \times$ microscope objectives. The light at the output of the waveguide was imaged using a CCD camera [25]. The basic concept of the setup used is illustrated in Fig. 7(a). Fig. 7(b) shows the image of the light at the output of the waveguide, confirming a single-mode guide at $632.8 \mathrm{~nm}$ [25]. In summary, these results demonstrate the feasibility of micromachining polymers containing organic compounds with controlled degradation of the active dye, which can be further explored for new applications in photonics.

3) Micromachining Polymers for Fabricating Superhydrofobic Surfaces: In the last few years, the development of methods to produce superhydrophobic surfaces has increased 


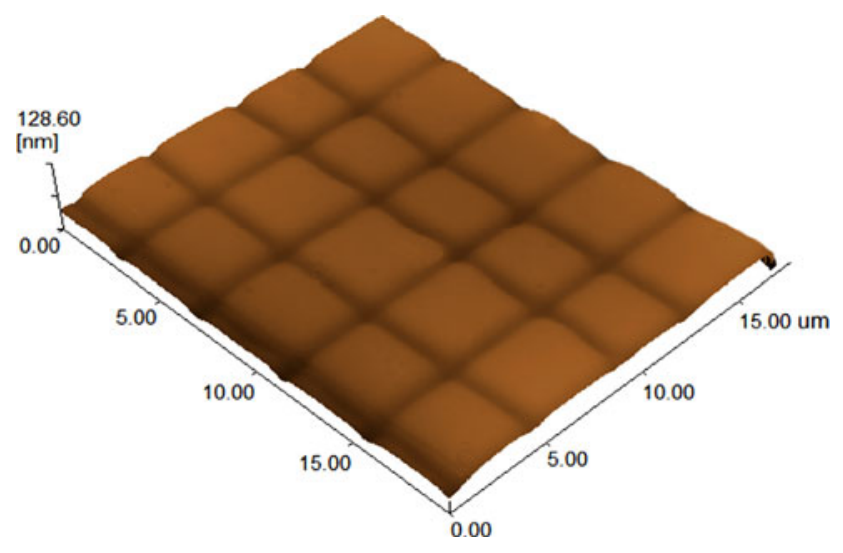

Fig. 8. Atomic force micrograph of a square-shaped-pillars morphology (4- $\mu \mathrm{m}$ period) micromachined in PODR1 with 100 -fs pulses and energy of $0.06 \mathrm{~nJ}$.

substantially, mainly motivated by applications in microfluidics, waterproof devices, low-friction coatings, and self-cleaning elements [57]-[59]. Considering that the surface wettability depends on the chemical nature of the material and also on the surface morphology, research has been conducted in these two directions to achieve materials with enhanced hydrophobicitiy. Therefore, attempts have been recently made on strategies to alter the materials' surface topology, aiming at the fabrication of superhydrophobic devices [58], [60]-[65]. Among the methods investigated, the use of ultrashort laser micromachining has been shown to be an interesting option. For instance, remarkable results have been obtained on structuring silicon surface [62], [66].

In recent years, we have been working on the use of ultrashort laser pulses to microstructure polymeric surfaces, aiming at the fabrication of surfaces with controllable hydrophobicity. We have produced by micromachining, polymeric surfaces with square-shaped pillar morphologies and distinct periodicities, from $5 \mu \mathrm{m}$ to $500 \mu \mathrm{m}$. These microstructuring were produced in $2-\mu \mathrm{m}$-thick films prepared with the commercial poly(1-methoxy-4-(O-disperse Red 1)-2,5-bis(2-methoxyethyl) benzene) (PODR1).

In Fig. 8, we show a typical atomic force microscopy image of the PODR1 sample, whose surface was microstructured using 100 -fs pulses at $800 \mathrm{~nm}$ ( $76 \mathrm{MHz}$ repetition rate), with an energy of $0.06 \mathrm{~nJ}$ per pulse. In this case, the periodicity of the microstructure is $4 \mu \mathrm{m}$. By using fs-laser pulses, we are able to fabricate microstructures with periods ranging from $1 \mu \mathrm{m}$ up to $100 \mu \mathrm{m}$, employing energies from $0.05 \mathrm{~nJ}$ up to $0.1 \mathrm{~nJ}$. Although the results achieved with this approach present very good resolution in regards to the width of the grooves, it is relatively limited to the depth of the inscribed structure (on the order of few nanometers). Such behavior is related to the TPA nature of the micromachining for this case, since the azochromophores in PODR1 do not present linear absorption at $800 \mathrm{~nm}$, but exhibit reasonable TPA cross section in the near-infrared $(\sim 300 \mathrm{GM})$. Because the two-photon excitation is highly confined to the focal volume, high resolution of the micromachining is obtained. Conversely, for the same reason, the depth of the structuring is

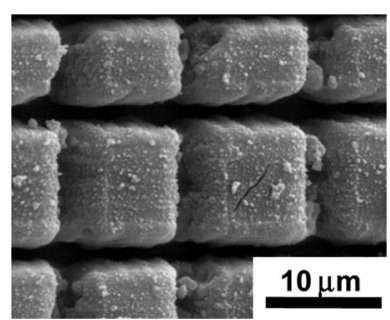

Fig. 9. Scanning electron microscopy image of PODR1 film microstructured with a period of $10 \mu \mathrm{m}$.

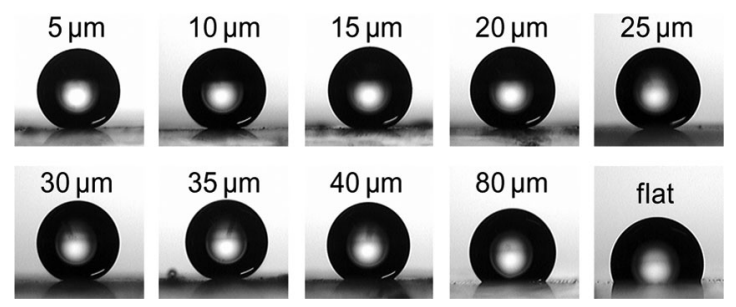

Fig. 10. Sequence of pictures of water droplets on top of the microstructured surface (square-shaped pillars) with different periodicities (noted on top of each image). The last image corresponds to the droplet on the flat (not microstructured) surface.

relatively small. These results indicate fs-laser micromachining of polymers containing two-photon absorbing dyes as an option when high precision in the microstructuring is needed, although they are somewhat limited when deep patterns are necessary.

As an illustration, Fig. 9 shows a scanning electron micrography of a PODR1 film, micromachined using 70-ps, 532-nm pulses from a $Q$-switched and mode-locked Nd:YAG laser, operating at a repetition rate of $850 \mathrm{~Hz}$. For obtaining such kind of result, pulse energies from $20 \mathrm{~nJ}$ up to $70 \mathrm{~nJ}$ are focused with a $0.65-\mathrm{NA}$ objective at a translation speed of $1 \mathrm{~mm} / \mathrm{s}$. The depth of the patterns, obtained through atomic force microscopy, is approximately $2 \mu \mathrm{m}$. After microstructuring the sample surface, they were treated with (heptadecafluoro-1,1,2,2tetrahydrodecyl)trichlorosilane to increase its natural hydrophobicity [62], [64].

Fig. 10 shows a sequence of images of a water droplet on surfaces microstructured with distinct periodicities (from $5 \mu \mathrm{m}$ to $80 \mu \mathrm{m})$, as well as on a flat surface. As can be seen, the contact angle increases from $108^{\circ}$, at the flat surface, to approximately $160^{\circ}$ on the microstructured surface with periods from $5 \mu \mathrm{m}$ to $30 \mu \mathrm{m}$, therefore reaching the superhydrophobic limit (contact angle higher than $150^{\circ}$ ). Such a result can be understood based on the Cassie-Baxter model [67], [68], which assumes that the liquid does not completely wet the surface because air pockets are trapped in the gaps of the rough surface. The aspect ratio of the morphologies fabricated is such that the entrapped air diminishes the contact area between water and polymer, resulting in a larger increase in the contact angle. Thus, the use of an ultrashort laser pulse seems to be an interesting approach to design the morphology of polymeric surfaces, allowing the control of the wetting properties. 
(a)
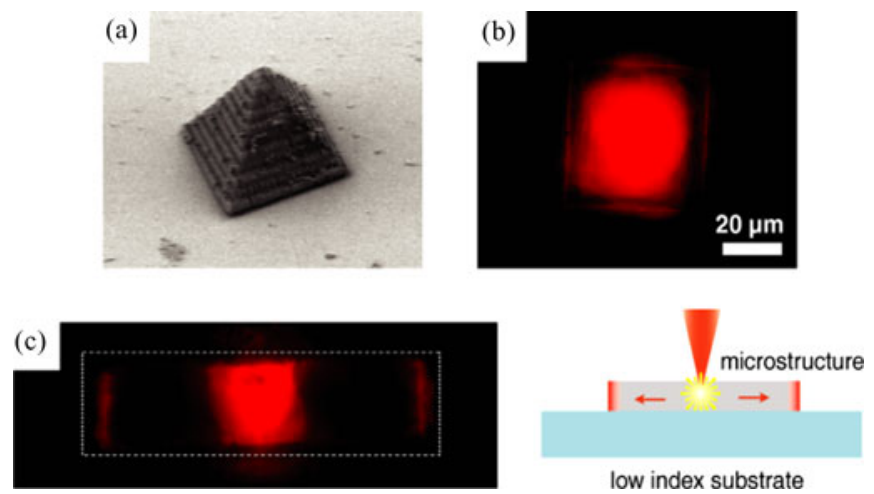

low index substrate

Fig. 11. (a) Scanning electron microscopy of a pyramidal microstructure containing MEH-PPV. (b) Fluorescence optical microscopy (top view image) of a pyramid. (c) Fluorescence optical microscopy (top view image) of waveguide containing MEH-PPV fabricated by TPA on a mesoporous silica substrate. Light is guided through the microstructure ends when it is excited at its center. On the right-hand side of (c) we display a schematic side view of the structure. Reprinted with permission from [87]. Copyright [2009], American Institute of Physics.

\section{B. TPA Polymerization Microfabrication of Doped Microstructures}

Regarding TPA polymerization microfabrication, considerable part of the studies reported in the literature focuses on undoped microstructures whose properties cannot be probed or altered by external sources. In the last few years, however, numerous research groups have seek for new resin formulations incorporating dyes or other materials of interest [69]-[73], leading to fabrication of active microstructures with chemical, biological, or optical properties, with prospective applications in optical data storage [73], photonic crystals [71], [74], [75], and biomedicine [76]-[79]. Here, we present some results our group has obtained based on a methodology to incorporate distinct dopants in the two-photon resin formulation, aiming at obtaining microstructures with unique properties for technological applications.

1) Microstructures Doped with a Conjugated Polymer: As mentioned earlier, MEH-PPV is a conjugated polymer known for its conductivity [80], electroluminescence [81], [82], and nonlinear optical properties [83]-[86]. In [87], a methodology was proposed to incorporate MEH-PPV into the basic resin in a guest-host strategy, in which the host consists of two triacrylate monomers. Initially, it is prepared an ethanol solution containing the photoinitiator Lucirin TPO-L. To this solution, MEH-PPV (up to $1 \%$ by weight) is added, and then this solution is mixed up for $2 \mathrm{~h}$. Ethanol is eliminated by evaporation at room temperature for $24 \mathrm{~h}$, yielding a viscous liquid.

Fig. 11(a) shows a scanning electron microscope image of a pyramidal microstructure containing MEH-PPV, fabricated by TPA polymerization, which presents good definition and structural integrity, indicating that the presence of MEH-PPV does not affect the fabrication process. Furthermore, MEH-PPV is retained in the microstructure, which can be seen by the fluorescence micrograph observed in Fig. 11(b). The structure containing MEH-PPV was excited with an average power of 1 $\mathrm{mW}$ by an Nd:YAG cw laser operating at $532 \mathrm{~nm}$.
Waveguides containing MEH-PPV have also been fabricated by the same method, using as substrates mesoporous silica films, which have a low refractive index $(n=1.185)$ throughout the visible spectrum and, therefore, minimize waveguiding losses [88]. Fig. 11(c) shows a fluorescence microscopy top view image of $100 \mu \mathrm{m}$-long waveguide fabricated on a mesoporous silica substrate, illuminated in its central region by the laser at $532 \mathrm{~nm}$. The MEH-PPV fluorescence is guided through the microstructure and scatters at both microstructure ends. When the experiment was carried out in waveguides fabricated on top of a conventional glass slide, no waveguiding was observed due to light coupling to the substrate. The right-hand side of Fig. 11(c) displays a schematic side view of the microstructure excitation and the corresponding waveguiding. The methodology employed to fabricate doped microstructures on top of mesoporous silica substrate is promising to be used in photonics applications, such as microLEDs and waveguides.

2) Microstructures Doped With Chitosan: Two-photon polymerized structures incorporating chitosan have also been fabricated and reported in [78]. For that purpose, a guest-host strategy was employed, in which the host consists of the two triacrylate monomers, and the guest material is chitosan $[(1 \rightarrow 4)-2$ amino-2-deoxy- $\beta$-D-glucan], which is a linear cationic polysaccharide obtained by deacetylation of chitin $[(1 \rightarrow 4)-2$ acetamide2 -deoxy- $\beta$-D-glucan], found in crustaceans shells [89]. Chitosan has appealing properties for being a biodegradable and biocompatible polymer, with applications in blood coagulation [90]-[92], soft tissue and bone regeneration [93], antibacterial action [94], nanostructured films [95], and drug delivery [96]. After purification, chitosan was dissolved in a solution of acetic acid in ethanol (7\% by volume), and mixed for 30 min with the basic resin and photoinitiator.

A scanning electron micrography of a two-photon polymerized structure containing chitosan is displayed in Fig. 12(a). The structure was fabricated from a solution containing 10 wt $\%$ of chitosan, with a laser average power of $20 \mathrm{~mW}$. The pattern displaying nanometer features on the surface of the structures was produced during the fabrication. Ideally, the chitosan should be retained within the structure without forming any kind of crosslinking, which would alter its chemical properties and, therefore, would be deleterious for bio-related application.

The Raman microscopy analysis of the structures with chitosan is displayed in Fig. 12(b) [78]. As the presence of chitosan does not affect the vibrational Raman spectrum of the resin, the crosslinking or other chemical interaction between the acrylic resin and the chitosan is negligible. The nonreaction between the acrylic resin and chitosan is desirable for biomedical applications, because it implies that the resin retains chitosan without altering any of its biological or chemical properties. The same spectrum [see Fig. 12(b)] shows a monotonically rising background, which is attributed to fluorescence from chitosan, also seen in the spectrum of neat chitosan (not shown) [78]. In addition, hardness measurements of specimens fabricated of acrylic resin with and without chitosan reveal that the biomolecules are not deleterious to the mechanical properties of the resin. Therefore, two-photon polymerized structures containing 

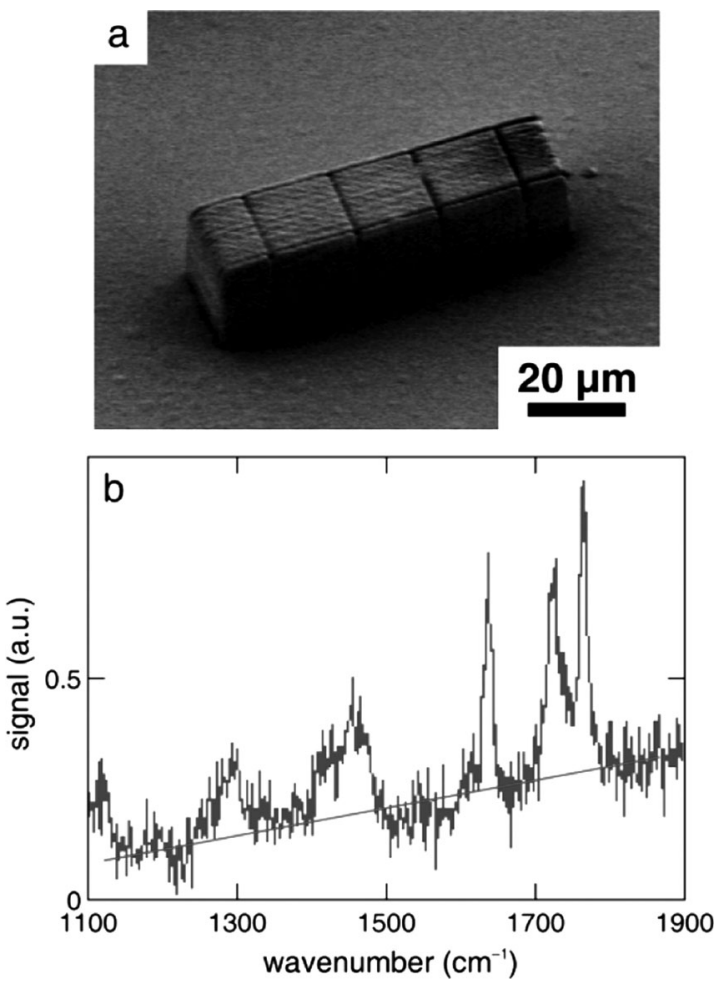

Fig. 12. (a) Scanning electron microscopy of a structure containing chitosan. (b) Raman spectrum of a two-photon polymerized microstructure doped with chitosan. Reprinted with permission from [78]. Copyright [2009], American Scientific publishers.
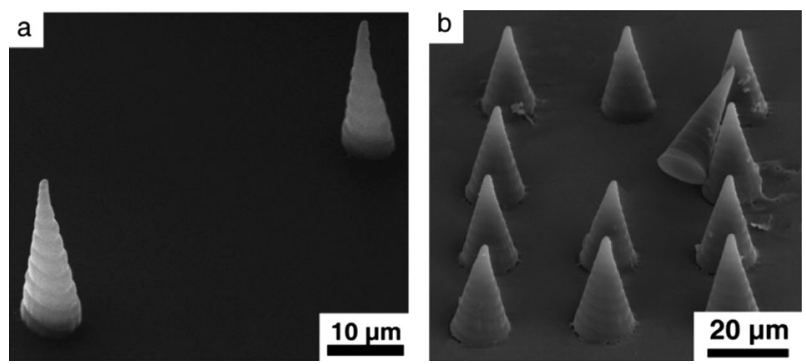

Fig. 13. Scanning electron microscopy images of conical structures containing rhodamine, fabricated by TPA polymerization.

chitosan could be an option to fabricate scaffolds for tissue engineering and bone reconstruction.

3) Microstructures Doped With Rhodamine 610: Microstructures containing rodhamine 610 have also been fabricated by TPA polymerization. The dye is well known for its chemical stability, strong luminescence, and nonlinear optical properties. As observed for the other reported formulations incorporating dyes, rhodamine is not deleterious for the physical properties of the structures. In Fig. 13, scanning electron microscopy of conical structures, fabricated by TPA polymerization, containing rhodamine $(0.5 \mathrm{wt} \%)$ is displayed.

The distribution of rhodamine into the polymeric structure was verified by confocal microscopy images of sections of a cubic structure, which are displayed in Fig. 14. The images, acquired by using as excitation a $\mathrm{cw}$ laser centered at $445 \mathrm{~nm}$,
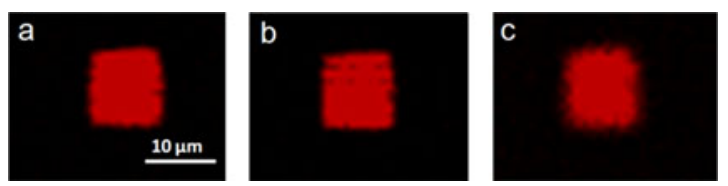

Fig. 14. Confocal microscopy images of planes of cubic structure containing rhodamine, fabricated by TPA polymerization. Images from (a) bottom, (b) $6.0 \mu \mathrm{m}$, and (c) $12 \mu \mathrm{m}$ from the bottom of the structure. Reprinted with permission from [97]. Copyright [2011], Springer Science+Business Media B.V.

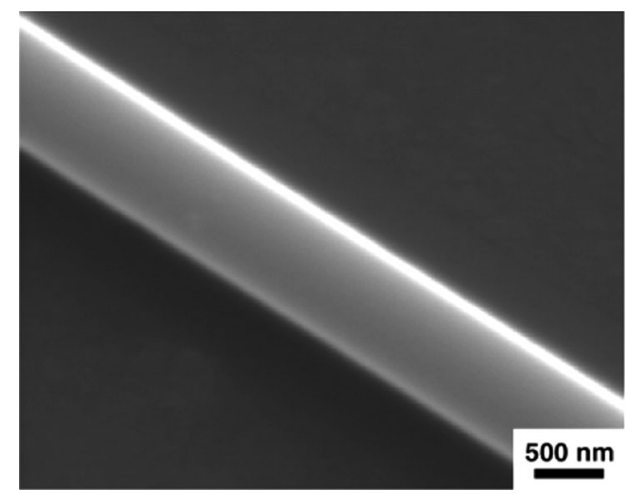

Fig. 15. Scanning electron microscopy image of a silica nanowire used to excite the fabricated polymeric microstructure.

were obtained in planes separated by $6 \mu \mathrm{m}$ and reveal that rhodamine is distributed throughout the structure [97].

4) Excitation of Fluorescent Microstructures Through Nanofibers: Microstructures doped with luminescent dyes render their optical properties, including linear and nonlinear absorption and luminescence, which might be useful for photonics devices. In this sense, it is desirable to optically integrate such microstructures, either to excite or collect light from them. Selective excitation of fluorescent two-photon polymerized structures can be achieved by employing nanowires. Silica nanowires, with diameters of approximately $1 \mu \mathrm{m}$, are produced using the fiber tapering technique (flame-heated fiber drawing) [98]. In Fig. 15, we show a scanning electron microscopy of a typical silica nanowire fabricated, which is used to excite the polymeric microstructures. The intense fluorescence of rhodamine-containing microstructures was obtained by using silica nanowires coupled to an $\mathrm{Ar}^{+}$laser.

By using this methodology, it was possible to selectively excite isolated microstructures in a controlled manner, as displayed by the optical microscopy images in Fig 16. We see the red emission arising from the rhodamine contained into the microstructure, which was excited by laser light at $514 \mathrm{~nm}$, coupled into the silica nanofiber. Fig. 16(a) shows an optical micrograph of the nanowire exciting three microstructures, while in Fig. 16(b) only one microstructure is being predominantly excited. Such an approach is the first step to integrate complex arrays of optical microstructures, aiming at the fabrication of micro-optical photonics circuitry [97]. 

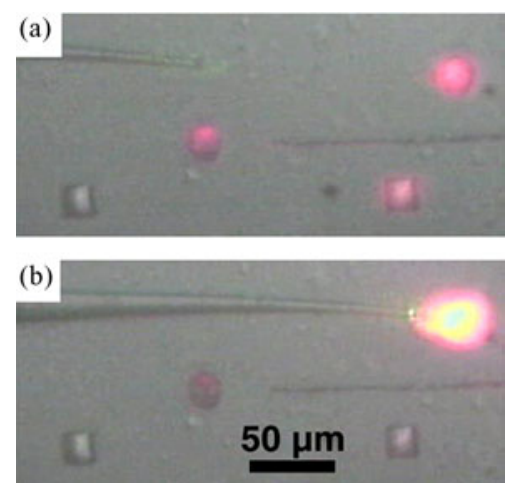

Fig. 16. Luminescence of microstructures doped with rhodamine, excited by light at $514 \mathrm{~nm}$ coupled into a silica nanowire. In (a) the light excites three microstructures while in (b) one microstructure is being predominantly excited.

\section{CONCLUSION}

We have demonstrated that fs laser is a useful tool to modify polymeric materials through micromachining and microfabrication via TPA polymerization. Specifically, micromachining of polymeric materials demonstrated that by a controlled degradation, removal or modification of polymeric material, grooves of wide range of depth can be recorded, which can be used to produce waveguides, superhydrophobic surfaces, etc. By using TPA polymerization, 3-D microstructures of high definition and structural integrity could also be fabricated. Distinct dopants can be incorporated into the basic resin, which, in general, are distributed throughout the microstructures, and preserve their properties after the fabrication, such as biocompatibility, luminescence, and waveguiding properties. By doping the resins used in TPA polymerization, one can greatly enhance the properties/performance of microstructures for applications in microdevices, such as microLEDs, waveguides, microfluidics, and scaffolds for tissue engineering.

\section{ACKNOWLEDGMENT}

The authors would like to acknowledge the support and interaction with previous students and collaborators.

\section{REFERENCES}

[1] X. Zhang, X. N. Jiang, and C. Sun, "Micro-stereolithography of polymeric and ceramic microstructures," Sens. Actuators A, Phys., vol. 77, pp. 149156, Oct. 1999.

[2] A. Javey, S. Nam, R. S. Friedman, H. Yan, and C. M. Lieber, "Layerby-layer assembly of nanowires for three-dimensional, multifunctional electronics," Nano Lett., vol. 7, pp. 773-777, Mar. 2007.

[3] J. W. Schultze and A. Bressel, "Principles of electrochemical micro- and nano-system technologies," Electrochimica Acta., vol. 47, pp. 3-21, Sep. 2001.

[4] Y. N. Xia and G. M. Whitesides, "Soft lithography," Ann. Rev. Mater. Sci., vol. 28, pp. 153-184, 1998.

[5] K. Kwok and W. K. S. Chiu, "Growth of carbon nanotubes by open-air laser-induced chemical vapor deposition," Carbon, vol. 43, pp. 437-446, 2005.

[6] S. Maruo, O. Nakamura, and S. Kawata, "Three-dimensional microfabrication with two-photon-absorbed photopolymerization," Opt. Lett., vol. 22, pp. 132-134, Jan. 1997.

[7] R. R. Gattass and E. Mazur, "Femtosecond laser micromachining in transparent materials," Nature Photon., vol. 2, pp. 219-225, Apr. 2008.
[8] K. M. Davis, K. Miura, N. Sugimoto, and K. Hirao, "Writing waveguides in glass with a femtosecond laser," Opt. Lett., vol. 21, pp. 1729-1731, Nov. 1996.

[9] A. M. Kowalevicz, V. Sharma, E. P. Ippen, J. G. Fujimoto, and K. Minoshima, "Three-dimensional photonic devices fabricated in glass by use of a femtosecond laser oscillator," Opt. Lett., vol. 30, pp. 10601062, May 2005.

[10] Y. Li, K. Yamada, T. Ishizuka, W. Watanabe, K. Itoh, and Z. X. Zhou, "Single femtosecond pulse holography using polymethyl methacrylate," Opt. Exp., vol. 10, pp. 1173-1178, Oct. 2002.

[11] S. Sowa, W. Watanabe, T. Tamaki, J. Nishii, and K. Itoh, "Symmetric waveguides in poly(methyl methacrylate) fabricated by femtosecond laser pulses," Opt. Exp., vol. 14, pp. 291-297, Jan. 2006.

[12] W. Watanabe, S. Sowa, T. Tamaki, K. Itoh, and J. Nishii, "Threedimensional waveguides fabricated in poly(methyl methacrylate) by a femtosecond laser," Jap. J. Appl. Phys. Part 2-Lett. Exp. Lett., vol. 45, pp. L765-L767, Aug. 2006.

[13] A. Zoubir, C. Lopez, M. Richardson, and K. Richardson, "Femtosecond laser fabrication of tubular waveguides in poly(methyl methacrylate)," Opt. Lett., vol. 29, pp. 1840-1842, Aug. 2004.

[14] N. Yurt, K. Mune, R. Naito, T. Fukuoka, A. Mochizuki, K. Matsumoto, G. Meredith, N. Peyghambarian, and G. E. Jabbour, "Fabrication and characterization of low-loss optical waveguides using a novel photosensitive polyimide," J. Lightwave Technol., vol. 23, pp. 1291-1294, Mar. 2005.

[15] E. H. Conradie and D. F. Moore, "SU-8 thick photoresist processing as a functional material for MEMS applications," J. Micromechanics Microengineering, vol. 12, pp. 368-374, Jul. 2002.

[16] G. T. Paloczi, J. Scheuer, and A. Yariv, "Compact microring-based wavelength-selective inline optical reflector," IEEE Photon. Technol. Lett., vol. 17, no. 2, pp. 390-392, Feb. 2005.

[17] W. H. Wong and E. Y. B. Pun, "Polymeric waveguide wavelength filters using electron-beam direct writing," Appl. Phys. Lett., vol. 79, pp. 35763578, Nov. 2001.

[18] P. N. Prasad, "Polymeric materials for nonlinear optics and photonics," Polymer, vol. 32, pp. 1746-1751, 1991.

[19] H. B. Sun and S. Kawata, "Two-photon photopolymerization and 3D lithographic microfabrication," in NMR-3D Analysis-Photopolymerization. vol. 170, Berlin, Germany: Springer-Verlag, 2004, pp. 169-273.

[20] C. B. Schaffer, A. Brodeur, J. F. Garcia, and E. Mazur, "Micromachining bulk glass by use of femtosecond laser pulses with nanojoule energy," Opt. Lett., vol. 26, pp. 93-95, Jan. 2001.

[21] D. B. Wolfe, J. B. Ashcom, J. C. Hwang, C. B. Schaffer, E. Mazur, and G. M. Whitesides, "Customization of poly(dimethylsiloxane) stamps by micromachining using a femtosecond-pulsed laser," Adv. Mater., vol. 15, pp. 62-65, Jan. 2003.

[22] E. N. Glezer, M. Milosavljevic, L. Huang, R. J. Finlay, T. H. Her, J. P. Callan, and E. Mazur, "Three-dimensional optical storage inside transparent materials," Opt. Lett., vol. 21, pp. 2023-2025, Dec. 1996.

[23] L. M. Tong, R. R. Gattass, I. Maxwell, J. B. Ashcom, and E. Mazur, "Optical loss measurements in femtosecond laser written waveguides in glass," Opt. Commun., vol. 259, pp. 626-630, Mar. 2006.

[24] C. A. D. Roeser, A. M. T. Kim, J. P. Callan, L. Huang, E. N. Glezer, Y. Siegal, and E. Mazur, "Femtosecond time-resolved dielectric function measurements by dual-angle reflectometry," Rev. Scientific Instrum., vol. 74, pp. 3413-3422, Jul. 2003.

[25] C. R. Mendonca, L. R. Cerami, T. Shih, R. W. Tilghman, T. Baldacchini, and E. Mazur, "Femtosecond laser waveguide micromachining of PMMA films with azoaromatic chromophores," Opt. Exp., vol. 16, pp. 200-206, Jan. 2008.

[26] D. F. Farson, H. W. Choi, C. M. Lu, and L. J. Lee, "Femtosecond laser bulk micromachining of microfluid channels in poly(methylmethacrylate)," $J$. Laser Appl., vol. 18, pp. 210-215, Aug. 2006.

[27] D. Cristea, P. Obreja, M. Kusko, E. Manea, and R. Rebigan, "Polymer micromachining for micro- and nanophotonics," Mater. Sci. Eng., C, vol. 26, pp. 1049-1055, Jul. 2006.

[28] M. S. Bakir, C. O. Chui, A. K. Okyay, K. C. Saraswat, and J. D. Meindl, "Integration of optical polymer pillars chip I/O interconnections with $\mathrm{Si}$ MSM photodetectors," IEEE Trans. Electron Devices, vol. 51, no. 7, pp. 1084-1090, Jul. 2004.

[29] J. Y. Cheng, C. W. Wei, K. H. Hsu, and T. H. Young, "Direct-write laser micromachining and universal surface modification of PMMA for device development," Sens. Actuators B, Chem., vol. 99, pp. 186-196, Apr. 15, 2004.

[30] T. H. R. Crawford, A. Borowiec, and H. K. Haugen, "Femtosecond laser micromachining of grooves in silicon with $800 \mathrm{~nm}$ pulses," Appl. Phys. A, Mater. Sci. Process., vol. 80, pp. 1717-1724, May 2005. 
[31] H. Klank, J. P. Kutter, and O. Geschke, " $\mathrm{CO}_{2}$-laser micromachining and back-end processing for rapid production of PMMA-based microfluidic systems," Lab Chip, vol. 2, pp. 242-246, 2002.

[32] W. Denk and K. Svoboda, "Photon upmanship: Why multiphoton imaging is more than a gimmick," Neuron, vol. 18, pp. 351-357, Mar. 1997.

[33] W. Kaiser and C. G. B. Garrett, "2-Photon Excitation in $\mathrm{CaF}_{2}$ : $\mathrm{Eu}^{2+}$," Phys. Rev. Lett., vol. 7, pp. 229-231, 1961.

[34] F. Terenziani, C. Katan, E. Badaeva, S. Tretiak, and M. Blanchard-Desce, "Enhanced two-photon absorption of organic chromophores: Theoretical and experimental assessments," Adv. Mater., vol. 20, pp. 4641-4678, Dec. 2008.

[35] G. S. He, L. S. Tan, Q. Zheng, and P. N. Prasad, "Multiphoton absorbing materials: Molecular designs, characterizations, and applications," Chem. Rev., vol. 108, pp. 1245-1330, Apr. 2008.

[36] K. D. Belfield, S. Yao, and M. V. Bondar, "Two-photon absorbing photonic materials: From fundamentals to applications," in Photoresponsive Polymers I, vol. 213. Berlin, Germany: Springer-Verlag, 2008, pp. 97156.

[37] S. Kawata, H. B. Sun, T. Tanaka, and K. Takada, "Finer features for functional microdevices-micromachines can be created with higher resolution using two-photon absorption," Nature, vol. 412, pp. 697-698, Aug. 2001.

[38] C. N. LaFratta, J. T. Fourkas, T. Baldacchini, and R. A. Farrer, "Multiphoton fabrication," in Angewandte Chemie -International Edition, vol. 46. New York: Wiley, 2007, pp. 6238-6258.

[39] K. S. Lee, R. H. Kim, D. Y. Yang, and S. H. Park, "Advances in 3D nano/microfabrication using two-photon initiated polymerization," Prog. Polym. Sci., vol. 33, pp. 631-681, Jun. 2008.

[40] S. R. Marder, J. L. Bredas, and J. W. Perry, "Materials for multiphoton 3D microfabrication," MRS Bull., vol. 32, pp. 561-565, Jul. 2007.

[41] G. R. Fowles, Introduction to Modern Optics, 2nd ed. New York: Dover, 1989.

[42] C. R. Mendonca, D. S. Correa, T. Baldacchini, P. Tayalia, and E. Mazur, "Two-photon absorption spectrum of the photoinitiator Lucirin TPO-L," Appl. Phys. A, Mater. Sci. Process., vol. 90, pp. 633-636, Mar. 2008.

[43] T. Baldacchini, C. N. LaFratta, R. A. Farrer, M. C. Teich, B. E. A. Saleh, M. J. Naughton, and J. T. Fourkas, "Acrylic-based resin with favorable properties for three-dimensional two-photon polymerization," J. Appl. Phys., vol. 95, pp. 6072-6076, Jun. 2004.

[44] R. H. Friend, R. W. Gymer, A. B. Holmes, J. H. Burroughes, R. N. Marks, C. Taliani, D. D. C. Bradley, D. A. Dos Santos, J. L. Bredas, M. Logdlund, and W. R. Salaneck, "Electroluminescence in conjugated polymers," Nature, vol. 397, pp. 121-128, Jan. 1999.

[45] J. H. Burroughes, D. D. C. Bradley, A. R. Brown, R. N. Marks, K. Mackay, R. H. Friend, P. L. Burns, and A. B. Holmes, "Light-emitting-diodes based on conjugated polymers," Nature, vol. 347, pp. 539-541, Oct. 1990

[46] C. R. Mendonca, S. Orlando, G. Cosendey, M. Winkler, and E. Mazur, "Femtosecond laser micromachining in the conjugated polymer MEHPPV," Appl. Surface Sci., vol. 254, pp. 1135-1139, Dec. 2007.

[47] D. G. J. Sutherland, J. A. Carlisle, P. Elliker, G. Fox, T. W. Hagler, I. Jimenez, H. W. Lee, K. Pakbaz, L. J. Terminello, S. C. Williams, F. J. Himpsel, D. K. Shuh, W. M. Tong, J. J. Jia, T. A. Callcott, and D. L. Ederer, "Photo-oxidation of electroluminescent polymers studied by core-level photoabsorption spectroscopy," Appl. Phys. Lett., vol. 68, pp. 2046-2048, Apr. 1996.

[48] W. Holzer, A. Penzkofer, M. Pichlmaier, D. D. C. Bradley, and W. J. Blau, "Photodegradation of some luminescent polymers," Chem. Phys., vol. 248, pp. 273-284, Oct. 1999.

[49] L. Eldada and L. W. Shacklette, "Advances in polymer integrated optics," IEEE J. Sel. Topics Quantum Electron., vol. 6, no. 1, pp. 54-68, Jan./Feb. 2000

[50] J. H. Si, J. R. Qiu, and K. Hirao, "Photofabrication of periodic microstructures in azodye-doped polymers by interference of laser beams," Appl. Phys. B, Lasers Opt., vol. 75, pp. 847-851, Dec. 2002.

[51] J. H. Si, J. R. Qiu, J. Y. Guo, G. D. Qian, M. Q. Wang, and K. Hirao, "Photoinduced birefringence of azodye-doped materials by a femtosecond laser," Appl. Opt., vol. 42, pp. 7170-7173, Dec. 2003.

[52] O. N. Oliveira, D. S. dos Santos, D. T. Balogh, V. Zucolotto, and C. R. Mendonca, "Optical storage and surface-relief gratings in azobenzenecontaining nanostructured films," Adv. Colloid Interface Sci., vol. 116, pp. 179-192, Nov. 2005.

[53] L. De Boni, L. Misoguti, S. C. Zilio, and C. R. Mendonca, "Degenerate two-photon absorption spectra in azoaromatic compounds," Chem. Phys. Chem., vol. 6, pp. 1121-1125, 2005.
[54] L. De Boni, J. J. Rodrigues, D. S. dos Santos, C. Silva, D. T. Balogh, O. N Oliveira, S. C. Zilio, L. Misoguti, and C. R. Mendonca, "Two-photon absorption in azoaromatic compounds," Chem. Phys. Lett., vol. 361, pp. 209-213, Jul. 2002.

[55] A. Galvan-Gonzalez, M. Canva, G. I. Stegeman, L. Sukhomlinova, R. J. Twieg, K. P. Chan, T. C. Kowalczyk, and H. S. Lackritz, "Photodegradation of azobenzene nonlinear optical chromophores: The influence of structure and environment," J. Opt. Soc. Amer. B, Opt. Phys., vol. 17, pp. 1992 2000, Dec. 2000

[56] A. Galvan-Gonzalez, M. Canva, G. I. Stegeman, R. Twieg, T. C Kowalczyk, and H. S. Lackritz, "Effect of temperature and atmospheric environment an the photodegradation of some Disperse Red 1-type polymers," Opt. Lett., vol. 24, pp. 1741-1743, Dec. 1999.

[57] H. Y. Erbil, A. L. Demirel, Y. Avci, and O. Mert, "Transformation of a simple plastic into a superhydrophobic surface," Science, vol. 299, pp. 1377-1380, 2003.

[58] R. Furstner, W. Barthlott, C. Neinhuis, and P. Walzel, "Wetting and selfcleaning properties of artificial superhydrophobic surfaces," Langmuir vol. 21, pp. 956-961, Feb. 2005.

[59] X. J. Feng and L. Jiang, "Design and creation of superwetting/antiwetting surfaces," Adv. Mater., vol. 18, pp. 3063-3078, 2006.

[60] R. Blossey, "Self-cleaning surfaces—virtual realities," Nat.Mater., vol. 2, pp. 301-306, May 2003.

[61] T. L. Sun, L. Feng, X. F. Gao, and L. Jiang, "Bioinspired surfaces with special wettability," Accounts Chem. Res., vol. 38, pp. 644-652, Aug. 2005.

[62] T. Baldacchini, J. E. Carey, M. Zhou, and E. Mazur, "Superhydrophobic surfaces prepared by microstructuring of silicon using a femtosecond laser," Langmuir, vol. 22, pp. 4917-4919, May 2006.

[63] D. Oner and T. J. McCarthy, "Ultrahydrophobic surfaces. Effects of topography length scales on wettability," Langmuir, vol. 16, pp. 7777-7782, Oct. 2000.

[64] W. L. Wu, Q. Z. Zhu, F. L. Qing, and C. C. Han, "Water repellency on a fluorine-containing polyurethane surface: Toward understanding the surface self-cleaning effect," Langmuir, vol. 25, pp. 17-20, Jan. 2009.

[65] M. Barberoglou, V. Zorba, E. Stratakis, E. Spanakis, P. Tzanetakis, S. H. Anastasiadis, and C. Fotakis, "Bio-inspired water repellent surfaces produced by ultrafast laser structuring of silicon," Appl. Surf. Sci., vol. 255 pp. 5425-5429, Mar. 2009.

[66] V. Zorba, E. Stratakis, M. Barberoglou, E. Spanakis, P. Tzanetakis, and C. Fotakis, "Tailoring the wetting response of silicon surfaces via fs laser structuring," Appl. Phys. A, Mater. Sci. Process., vol. 93, pp. 819-825, Dec. 2008.

[67] A. B. D. Cassie and S. Baxter, "Wettability of porous surfaces," Trans. Faraday Soc., vol. 40, pp. 0546-0550, 1944.

[68] N. A. Patankar, "On the modeling of hydrophobic contact angles on rough surfaces," Langmuir, vol. 19, pp. 1249-1253, Feb. 2003.

[69] T. S. Drakakis, G. Papadakis, K. Sambani, G. Filippidis, S. Georgiou, E. Gizeli, C. Fotakis, and M. Farsari, "Construction of three-dimensional biomolecule structures employing femtosecond lasers," Appl. Phys. Lett., vol. 89, p. 144108 , Oct. 2006.

[70] H. B. Sun, T. Tanaka, K. Takada, and S. Kawata, "Two-photon photopolymerization and diagnosis of three-dimensional microstructures containing fluorescent dyes," Appl. Phys. Lett., vol. 79, pp. 1411-1413, Sep. 2001.

[71] M. Farsari, A. Ovsianikov, M. Vamvakaki, I. Sakellari, D. Gray, B. N Chichkov, and C. Fotakis, "Fabrication of three-dimensional photonic crystal structures containing an active nonlinear optical chromophore," Appl. Phys. A, Mater. Sci. Process., vol. 93, pp. 11-15, Oct. 2008.

[72] N. Takeyasu, T. Tanaka, and S. Kawata, "Fabrication of 3D metal/polymer microstructures by site-selective metal coating," Appl.Phys. A, Mater. Sci. Process., vol. 90, pp. 205-209, Feb. 2008

[73] C. R. Mendonca, T. Baldacchini, P. Tayalia, and E. Mazur, "Reversible birefringence in microstructures fabricated by two-photon absorption polymerization," J. Appl. Phys., vol. 102, p. 013109, Jul. 2007.

[74] B. H. Cumpston, S. P. Ananthavel, S. Barlow, D. L. Dyer, J. E. Ehrlich, L. L. Erskine, A. A. Heikal, S. M. Kuebler, I. Y. S. Lee, D. McCord-Maughon, J. Q. Qin, H. Rockel, M. Rumi, X. L. Wu, S. R. Marder, and J. W. Perry, "Two-photon polymerization initiators for three-dimensional optical data storage and microfabrication," Nature, vol. 398, pp. 51-54, Mar. 1999.

[75] J. Serbin, A. Ovsianikov, and B. Chichkov, "Fabrication of woodpile structures by two-photon polymerization and investigation of their optical properties," Opt. Exp., vol. 12, pp. 5221-5228, Oct. 2004. 
[76] A. Ovsianikov, B. Chichkov, O. Adunka, H. Pillsbury, A. Doraiswamy, and R. J. Narayan, "Rapid prototyping of ossicular replacement prostheses," Appl. Surface Sci., vol. 253, pp. 6603-6607, May 2007.

[77] R. Liska, M. Schuster, R. Infuhr, C. Tureeek, C. Fritscher, B. Seidl, V. Schmidt, L. Kuna, A. Haase, F. Varga, H. Lichtenegger, and J. Stampfl, "Photopolymers for rapid prototyping," J. Coatings Technol. Res., vol. 4, pp. 505-510, Dec. 2007.

[78] D. S. Correa, P. Tayalia, G. Cosendey, D. S. Dos Santos, Jr., R. F. Aroca, E. Mazur, and C. R. Mendonca, "Two-photon polymerization for fabricating structures containing the biopolymer chitosan," J. Nanosci. Nanotechnol., vol. 9, pp. 5845-5849, 2009.

[79] P. Tayalia, C. R. Mendonca, T. Baldacchini, D. J. Mooney, and E. Mazur, "3D cell-migration studies using two-photon engineered polymer scaffolds," Adv. Mater., vol. 20, pp. 4494-4498, Dec. 2008.

[80] G. Yu, J. Gao, J. C. Hummelen, F. Wudl, and A. J. Heeger, "Polymer photovoltaic cells: Enhanced efficiencies via a network of internal donoracceptor heterojunctions," Science, vol. 270, pp. 1789-1791, Dec. 1995.

[81] I. D. Parker, "Carrier tunneling and device characteristics in polymer light-emitting-diodes," J. Appl. Phys., vol. 75, pp. 1656-1666, Feb. 1994

[82] T. Q. Nguyen, I. B. Martini, J. Liu, and B. J. Schwartz, "Controlling interchain interactions in conjugated polymers: The effects of chain morphology on exciton-exciton annihilation and aggregation in MEH-PPV films," J. Phys. Chem. B, vol. 104, pp. 237-255, Jan. 2000.

[83] S. L. Oliveira, D. S. Correa, L. De Boni, L. Misoguti, S. C. Zilio, and C. R. Mendonca, "Two-photon absorption cross-section spectrum of a pi-conjugated polymer obtained using the white-light continuum Z-scan technique," Appl. Phys. Lett., vol. 88, p. 021911, Jan. 2006.

[84] L. De Boni, A. A. Andrade, D. S. Correa, D. T. Balogh, S. C. Zilio, L. Misoguti, and C. R. Mendonca, "Nonlinear absorption spectrum in MEH-PPV/chloroform solution: A competition between two-photon and saturated absorption processes," J. Phys. Chem. B, vol. 108, pp. 52215224, Apr. 2004

[85] S.-J. Chung, G. S. Maciel, H. E. Pudavar, T.-C. Lin, G. S. He, J. Swiatkiewicz, P. N. Prasad, D. W. Lee, J.-I. Lin, and M. Menard, "Twophoton properties and excitation dynamics of poly(p-phenylenevinylene) derivatives carrying phenylanthracence and branched alkoxy pendents," J. Phys. Chem. A, vol. 106, pp. 7512-7520, 2002.

[86] D. S. Correa, L. De Boni, D. T. Balogh, and C. R. Mendonca, "Threeand four-photon excitation of poly(2-methoxy-5-(2'-ethylhexyloxy)-1,4phenylenevinylene) (MEH-PPV)," Adv. Mater., vol. 19, pp. 2653-2656, Sep. 2007

[87] C. R. Mendonca, D. S. Correa, F. Marlow, T. Voss, P. Tayalia, and E. Mazur, "Three-dimensional fabrication of optically-active microstructures containing MEH-PPV," Appl. Phys. Lett., vol. 95, p. 113309, 2009.

[88] D. Konjhodzic, H. Bretinger, U. Wilczok, A. Dreier, A. Ladenburger, M. Schmidt, M. Eich, and F. Marlow, "Low-n mesoporous silica films: Structure and properties," Appl. Phys. A, Mater. Sci. Process., vol. 81, pp. 425-432, Jul. 2005.

[89] M. Kumar, "A review of chitin and chitosan applications," Reactive Funct. Polym., vol. 46, pp. 1-27, Nov. 2000.

[90] Y. Okamoto, R. Yano, K. Miyatake, I. Tomohiro, Y. Shigemasa, and S. Minami, "Effects of chitin and chitosan on blood coagulation," Carbohydrate Polym., vol. 53, pp. 337-342, Aug. 2003.

[91] K. Y. Lee, W. S. Ha, and W. H. Park, "Blood compatibility and biodegradability of partially n-acylated chitosan derivatives," Biomaterials, vol. 16, pp. 1211-1216, Nov. 1995

[92] S. Sagnella and K. Mai-Ngam, "Chitosan based surfactant polymers designed to improve blood compatibility on biomaterials," Colloids Surfaces B, Biointerf., vol. 42, pp. 147-155, May 2005.

[93] H. W. Tong and M. Wang, "Electrospinning of aligned biodegradable polymer fibers and composite fibers for tissue engineering applications," J. Nanosci. Nanotechnol., vol. 7, pp. 3834-3840, Nov. 2007.

[94] Q. L. Hu, B. Q. Li, M. Wang, and J. C. Shen, "Preparation and characterization of biodegradable chitosan/hydroxyapatite nanocomposite rods via in situ hybridization: A potential material as internal fixation of bone fracture," Biomaterials, vol. 25, pp. 779-785, Feb. 2004.

[95] D. S. dos Santos, A. Bassi, J. J. Rodrigues, L. Misoguti, O. N. Oliveira and C. R. Mendonca, "Light-induced storage in layer-by-layer films of chitosan and an azo dye," Biomacromolecules, vol. 4, pp. 1502-1505, Nov./Dec. 2003

[96] A. Berthold, K. Cremer, and J. Kreuter, "Preparation and characterization of chitosan microspheres as drug carrier for prednisolone sodium phosphate as model for antiinflammatory drugs," J. Control. Release, vol. 39, pp. 17-25, Mar. 1996
[97] D. S. Correa, V. Tribuzi, M. R. Cardoso, L. Misoguti, and C. R. Mendonca, "Selective excitation through tapered silica fibers of fluorescent two-photon polymerized structures," Appl. Phys. A, Mater. Sci., vol. 102, pp. 435-439, 2011.

[98] L. M. Tong, R. R. Gattass, J. B. Ashcom, S. L. He, J. Y. Lou, M. Y. Shen, I. Maxwell, and E. Mazur, "Subwavelength-diameter silica wires for lowloss optical wave guiding," Nature, vol. 426, pp. 816-819, Dec. 2003.

Daniel S. Corrêa received the B.E. (Materials) degree from the Universidade Federal de São Carlos and the Doctorate degree in materials science and engineering from Universidade de São Paulo, in 2004 and 2009, respectively.

From 2009 to 2010, he was a Postdoctoral Fellow at the Instituto de Física de São Carlos, Universidade de São Paulo. He is currently working as a Researcher at Embrapa Instrumentação, São Carlos, Brazil. His research interest is focused on microfabrication in polymeric materials using femtosecond laser, and also on the study of nonlinear optical absorption of organic materials.

Marcos R. Cardoso received the Bachelor's degree in physics in 2002 from the Universidade Estadual Paulista Júlio de Mesquita Filho, Rio Claro, Brazil, and the Master' degree in 2005 and the Doctorate degree in 2010 in materials science and engineering both from the Universidade de São Paulo, São Carlos, Brazil.

He is currently working as a Researcher at the Instituto de Física de Carlos, Universidade de São Paulo. His research interest is focused on micromachining of polymeric materials using ultrashort laser pulses and optical storage.

Vinicius Tribuzi received the Bachelor's and Master's degrees in physics both from the Universidade de São Paulo, São Carlos, Brazil, in 2006 and 2009, respectively. He is currently working toward the Doctorate degree at the Instituto de Física de Carlos, Universidade de São Paulo.

His research interest is focused on the fabrication of polymeric microstructures using femtosecond lasers.

Lino Misoguti received the Ph.D. degree in materials science and engineering from the University of São Paulo, São Carlos, Brazil, in 1999.

From 2000 to 2001, he was involved on high-harmonic generation and wavemixing processes in gases using femtosecond pulses at JILA, University of Colorado, during his postdoctoral research. Currently, he is a Faculty Member at the Instituto de Física de São Carlos, University of São Paulo, where he has been working on ultrafast pulse application on nonlinear optics and coherent control of light and matter interaction.

Cleber R. Mendonça received the Ph.D. degree in physics in 2000 from the Universidade de São Paulo, São Carlos, Brazil.

In 2001, he worked as a Postdoctoral Researcher at the College of Optics and Photonics (CREOL), University of Central Florida. In 2001, he joined the Instituto de Física de São Carlos, Universidade de São Paulo, where he is currently a Professor in the Department of Physics and Material Science. From 2005 to 2007, he was a Visiting Scientist at the Physics Department, Harvard University, where he worked on femtosecond-laser microfabrication and ultrafast dynamics in solids. His current research interests are nonlinear optical processes in organic materials, coherent control of the light-mater interaction and ultrashort laser microfabrication in polymers. 